\title{
Sea Level Determination in the Spanish Coast Using GNSS-R ${ }^{+}$
}

\author{
Víctor Puente * and Marcelino Valdés \\ National Geographic Institute of Spain, General Ibañez de Ibero 3, 28003 Madrid, Spain \\ * Correspondence: vpuente@fomento.es \\ + Presented at the II Congress in Geomatics Engineering, Madrid, Spain, 26-27 June 2019. \\ Published: 15 July 2019
}

\begin{abstract}
GNSS reflectometry (GNSS-R) a technique for the study of variations in the height of sea level and inland waters, and for the study of soil moisture, based on the comparison of the direct and reflected noise signal. The main advantage of this method is that allows the connection between sea level measurements and the global reference frame. The purpose of this contribution is to present the GNSS-R analysis service at the Geodesy department of the National Geographic Institute of Spain and to compare the sea level time series determined by means of GNSS-R with tide gauge measurements. Two different GNSS-R methods using multi-constellation and multi-frequency data are compared: Lomb-Scargle Periodogram and Inverse Modelling. This analysis is performed for 3 GNSS antennas collocated to tide gauges along the Spanish coast. Eventually, advantages and disadvantages of this method are discussed.
\end{abstract}

Keywords: GNSS-R; sea level; tide gauge; SNR

\section{Introduction}

GNSS reflectometry (GNSS-R) is a technique for sensing the near-field environment of a permanent GNSS station based on the usage of reflected signals recorded as oscillations in signal-tonoise ratio (SNR). Several applications of this methodology can be found in the literature. For instance, to measure sea level height [1], soil moisture [2] or snow depth [3].

Regarding local sea level height monitoring by means of GNSS-R, the usual methodology is based on the spectral analysis of SNR using Lomb-Scargle Periodogram method (in the following, LSP method). Recently, Strandberg [4] proposed a new algorithm known as Inverse Modelling method (in the following, IM method) which models sea surface heights as a continuous function using B-splines. In this work both methods are compared in terms of accuracy and correlation with respect to tide gauge records for a co-located GNSS permanent station. The better method is later used to analyse long term sea level height for three GNSS permanent stations located by the sea.

\section{Methodology}

GNSS-R for local sea height retrieval is only valid for stations located near the sea so that signals reflected in the sea reach the GNSS antenna. Regardless the method used to estimate sea level, the following steps are needed prior to height estimation:

1. Define azimuth range and elevation range of interest; i.e., reflection zone in the sea.

2. Extract SNR data from RINEX files.

3. Select satellite passes that fullfil azimuth and elevation conditions.

4. Convert SNR to linear units and remove temporal trend (e.g., removing a second order polynomial, although there are authors that use higher degree polynomials [5]). 
Eventually, filtered SNR data is used to estimate sea height using LSP or IM methods, which are described in the following subsections.

\subsection{Lomb-Scargle Periodogram Method}

Lomb-Scargle Periodogram method is based on the following functional model that relates detrended SNR ( $\delta S N R)$ and the height of the reflecting surface $(h)$, as reflected in Equation (1):

$$
\operatorname{\partial SNR}(\mathrm{e})=\left[A \cos \frac{4 \pi h}{\lambda} \sin e+\varphi\right] .
$$

where $A$ is the amplitude of the wave, $\lambda$ is the wavelength, $e$ is the elevation angle and $\varphi$ is a phase constant. LSP method performs arc-wise inversion of SNR data on a satellite system and wavelength basis. The dominant multipath frequency is estimated using the Lomb Scargle Periodogram, which is the appropriate technique when observations are not evenly sampled, which is the case due to the dependence on the sine of the elevation angle.

\subsection{Inverse Modelling Method}

Inverse Modelling method [4] proposes the following model for sea height retrieval through GNSS-R:

$$
\operatorname{dSNR}(\mathrm{e})=\left[\mathrm{C}_{1} \sin \frac{4 \pi h}{\lambda} x+\mathrm{C}_{2} \sin \frac{4 \pi h}{\lambda} x\right] \mathrm{e}^{-4 \mathrm{k}^{2} \Lambda x^{2}} .
$$

where $\delta \mathrm{SNR}$ is the detrended SNR, $\mathrm{C}_{1}$ and $\mathrm{C}_{2}$ are constants per satellite system and wavelength, $\Lambda$ is a roughness parameter, $\mathrm{k}$ is the wave number, $\lambda$ is the wavelength, $x$ is equal to $\sin \mathrm{e}$ and $h$ is the height of the reflecting surface. The main advantage of this method is that models sea surface height as a smooth function and that allows combining data from several constellations.

The height of the reflecting surface is in turn modelled through B-Spline functions and sea height is estimated as node values of the B-spline parametrization. In this work, quadratic B-Spline functions are used. For further details of this model see [4].

\section{Results}

The two methods described in the previous section were applied to the data of BCL1 station, located at the port of Barcelona. This station is part of the Spanish GNSS Reference Stations Network (ERGNSS) and is co-located to a RADAR tide gauge belonging to the Spanish Port System network. This GNSS station is multi-GNSS capable (GPS, GLONASS, Galileo and Beidou).

For LSP method, Fortran and MATLAB routines provided by Roesler and Larson [6] were adapted to process time series of SNR data. Concerning IM method, ad-hoc MATLAB routines were implemented.

One year of data (2018) was analysed and the results in terms of accuracy (standard deviation) and correlation with respect to the RADAR tide gauge records are provided in Table 1. As previously mentioned, LSP method can be only applied per GNSS constellation and frequency whereas IM method allows the combination of multi-GNSS data.

Table 1. Results of GNSS-R for sea height estimation in BCL1 station.

\begin{tabular}{ccc}
\hline Method & Standard Deviation $\mathbf{( c m )}$ & Correlation \\
\hline LSP GPS, L1 & 5.26 & 0.91 \\
LSP GPS, L2 & 7.74 & 0.83 \\
LSP GLONASS, L1 & 5.53 & 0.90 \\
LSP GLONASS, L2 & 5.37 & 0.90 \\
LSP GALILEO, E1 & 7.44 & 0.84 \\
LSP GALILEO, E5 & 12.52 & 0.62 \\
IM (GPS+GLO+GAL+BDS) & 3.19 & 0.96 \\
\hline
\end{tabular}


Inverse Modelling method provides the better results in terms of accuracy and correlation. The results are in line with those obtained in [4].

Once the better method has been identified, it is applied to the data of three stations belonging to the ERGNSS for a longer period of time (mid-2016 to end-2018). The stations analysed are BCL1, MAL1 and ALAC (Figure 1), all of them located in the Mediterranean coast (Figure 1, right). In all cases, the data sampling used was $30 \mathrm{~s}$.
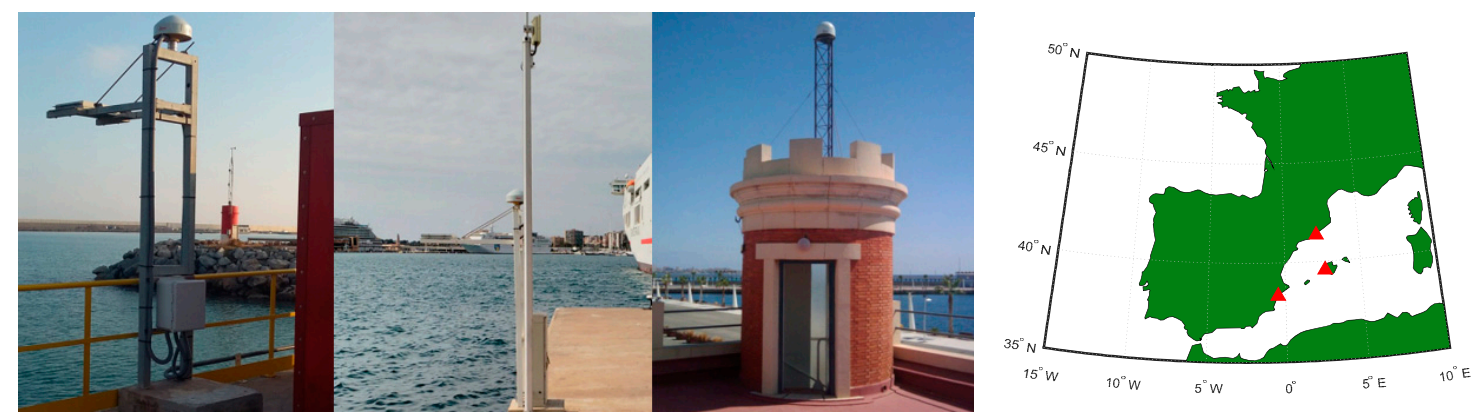

Figure 1. BCL1, MAL1 and ALAC GNSS antennas. General location map (right).

MAL1 is placed in the port of Palma de Mallorca and it is co-located to a RADAR tide gauge belonging to the Spanish Port System network. ALAC is located at the port of Alicante and is close to ALAC2 tide gauge, which is part of the National Geographic Institute tide gauges network. Both stations register GPS, GLONASS and Galileo data.

Figure 2 (up) shows the comparison of tide gauge record and GNSS-R derived sea height using IM method for BCL1 station. The standard deviation of the differences is $3.9 \mathrm{~cm}$ and the correlation is 93.2. In order to compare both series, the mean difference was removed. Figure 2 (down) shows the comparison of tide gauge record and GNSS-R derived sea height using IM method for MAL1 station. The standard deviation of the differences is $3.4 \mathrm{~cm}$ and the correlation is 96.8 . This station suffered several data gaps during the period analysed.
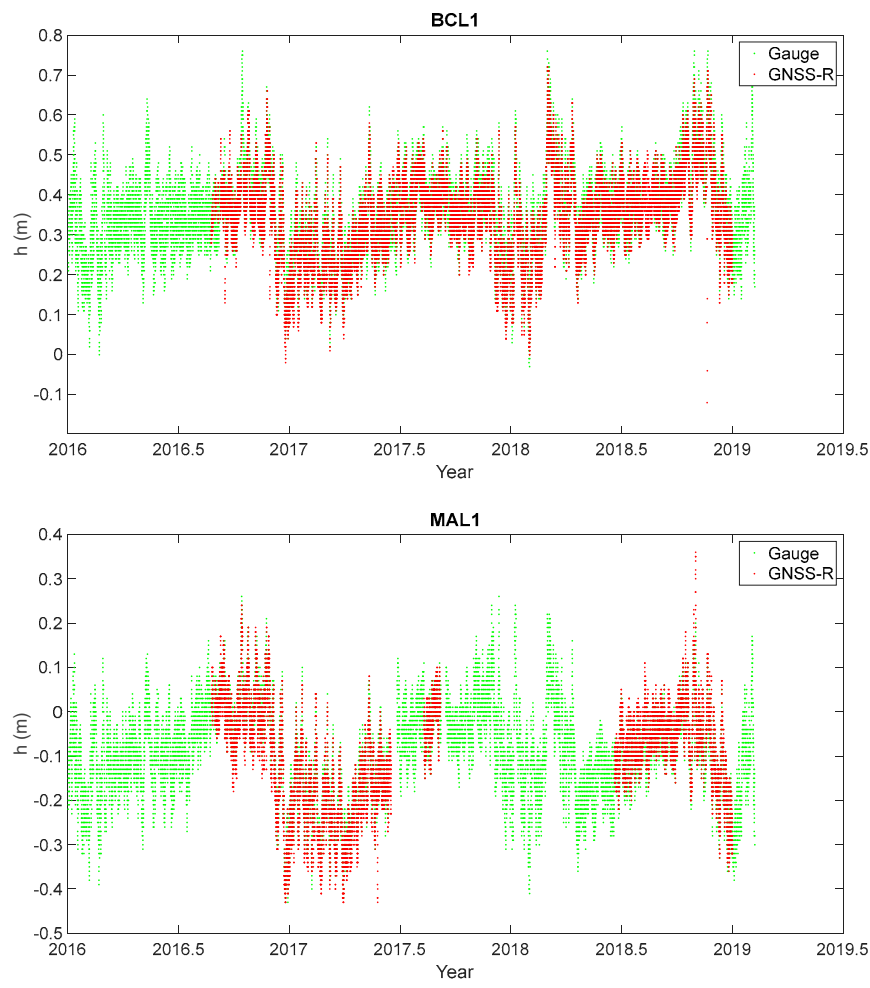

Figure 2. Sea level at BCL1 (up) and MAL1 (down) from GNSS-R IM and tide gauge. 
The analysis of ALAC data led to not consistent results. The algorithm has not provided good results for several periods. The root cause is still to be found but it may be related to the fact that the GNSS antenna is $40 \mathrm{~m}$ off the sea.

\section{Conclusions and Future Work}

GNSS-R methodology has been successfully applied to the data recorded by two co-located GNSS permanent stations (BCL1 and MAL1). The accuracy of the method is around $3 \mathrm{~cm}$, which is line with other works on this topic. The results on ALAC station require further analysis.

In the future, it is expected to expand the analysis to other stations with higher tide amplitude (e.g., Huelva), to implement a real time estimation service based on the method proposed by [7] and also to further analyse the offset between GNSS-R and tide gauge records applying the correction due to bending effect [5], which has not been dealt with in this work.

The main advantage of the technique discussed in this contribution is the capability of monitoring absolute mean sea level in Spain referred to the International Terrestrial Reference Frame (ITRF). Finally, a SWOT analysis of GNSS-R for sea level monitoring (Table 2) is provided:

Table 2. SWOT analysis of GNSS-R for sea level monitoring.

\begin{tabular}{|c|c|}
\hline Strengths & Weaknesses \\
\hline $\begin{array}{ll}\text { - } & \text { Direct link to the ITRF } \\
\text { - } & \text { Low maintenance } \\
\text { - } & \text { Two-fold application of GNSS station } \\
\end{array}$ & $\begin{array}{ll}\text { - } & \text { Worse accuracy than RADAR tide gauges } \\
\text { - } & \text { Ad-hoc configuration for each station (azimuth } \\
\text { and elevation range, a priori value) }\end{array}$ \\
\hline Opportunities & Threats \\
\hline 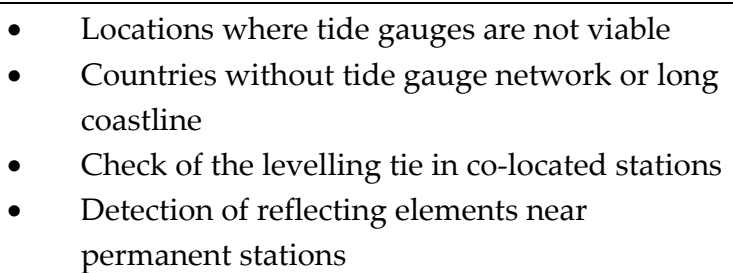 & - $\quad$ Low cost tide gauges \\
\hline
\end{tabular}

Acknowledgments: We acknowledge Spanish Port System the provision of RADAR tide gauge data that was used as reference data for Barcelona and Palma de Mallorca stations.

\section{References}

1. Löfgren, J.S.; Haas, R. Sea level measurements using multi-frequency GPS and GLONASS observations. EURASIP J. Adv. Signal Process. 2014, 2014, 50.

2. Larson, K.M.; Small, E.E.; Gutmann, E.; Bilich, A.; Braun, J.; Zavorotny, V. Use of GPS receivers as a soil moisture network for water cycle studies. Geophys. Res. Lett. 2008, 35, L24405.

3. Larson, K.M.; Gutmann, E.; Zavorotny, V.U.; Braun, J.J.; Williams, M.; Nievinski, F.G. Can we measure snow depth with GPS receivers? Geophys. Res. Lett. 2009, 36, L17502.

4. Strandberg, J.; Hobiger, T.; Haas, R. Improving GNSS-R sea level determination through inverse modeling of SNR data. Radio Sci. 2016, 51, 1286-1296.

5. Santamaría-Gómez, A.; Watson, C.; Gravelle, M.; King, M.; Wöppelmann, G. Levelling co-located GNSS and tide gauge stations using GNSS reflectometry. J. Geod. 2015, 89, 241.

6. Roesler, C.; Larson, K.M. Software tools for GNSS interferometric reflectometry (GNSS-IR). GPS Solut. 2018, $22,80$.

7. Strandberg, J.; Hobiger, T.; Haas, R. Real-time sea-level monitoring using Kalman filtering of GNSS-R data. GPS Solut. 2019, 23, 61. 